\title{
EFEKTIVITAS PENGGUNAAN ELECTRONIC FLIGHT BAG DAN BUDAYA KESELAMATANTERHADAP KINERJA KESELAMATAN PENERBANGAN DI PT. GARUDA INDONESIA
}

\author{
* Hendro Kuncoro ${ }^{1}$, Vica Harahap ${ }^{2}$ \\ ${ }^{1,2}$ Institut Transportasi dan Logistik Trisakti, Jakarta, Indonesia
}

*Email Korespondensi:

hendrokuncoro05@gmail.com

\section{ARTIKEL INFORMASI}

Diterima:

24 Juni 2021

Direvisi:

12 Juli 2021

Dipublikasi:

22 Juli 2021

\begin{abstract}
ABSTRAK
Tujuan penelitian ini adalah untuk mengetahui pengaruh efektivitas penggunaan electronic flight bag dan budaya keselamatan terhadap kinerja keselamatan penerbangan Garuda Indonesia. Data yang digunakan dalam penelitian ini adalah data primer yang diperoleh dengan cara penyebaran kuesioner yang didistribusikan secara online kepada sampel penerbang Garuda Indonesia sebanyak 35 orang yang khusus menerbangkan pesawat jenis Airbus A330. Teknik analisis yang digunakan adalah analisis deskriptif kuantitatif. Perhitungan data dibantu dengan paket SPSS versi 25 menunjukkan hubungan antar variabel yang sangat kuat, searah dan positif. Hasil olah data lainnya menununjukan efektivitas penggunaan electronic flight bag dan budaya keselamatan berpengaruh positif dan signifikan terhadap kinerja keselamatan penerbangan sebesar 78,8\%, dimana budaya keselamatan berpengaruh dominan terhadap mempengaruhi kinerja keselamatan penerbangan.
\end{abstract}

Kata Kunci: Kinerja Keselamatan, Efektivitas, Electronic Flight Bag, Budaya Keselamatan

\section{PENDAHULUAN}

UU no 1 tahun 2009 menyatakan bahwa penerbangan merupakan bagian dari sistem transportasi nasional yang mempunyai karakteristik mampu bergerak dalam waktu cepat, menggunakan teknologi tinggi, padat modal, manajemen yang andal, serta memerlukan potensi dan peranannya yang efektif dan efisien, serta membantu terciptanya pola distribusi nasional yang mantap dan dinamis. Keselamatan merupakan prioritas utama dalam dunia penerbangan sehingga perlu adanya standar keselamatan yang optimal sesuai dengan perkembangan teknologi sekarang ini. Setiap individu atau instansi harus mematuhi setiap standar atau aturan yang dikeluarkan oleh badan internasional seperti Internasional Civil Aviation Organization (ICAO), Federal Aviation Administration (FAA), the European Aviation Safety Agency (EASA) dimana tanggung jawabnya dilaksanakan oleh Joint Aviation Authority (JAA), yang merupakan anggota dari Masyarakat Ekonomi Eropa (MEE). 
Semua kegiatan penerbangan dapat menimbulkan risiko yang tidak diinginkan yaitu berupa kecelakaan pesawat. Menurut FAA (Federal Aviation Administration) terdapat 3 faktor penyebab kecelakaan yaitu faktor cuaca (weather) sebesar 13,2\%, faktor pesawat sebesar 27,1\% dan hampir $66 \%$ dari keseluruhan kecelakaan (accidents) maupun insiden (incidents) penerbangan disebabkan oleh faktor kesalahan manusia (human error). Laporan resmi KNKT menyatakan bahwa faktor keselamatan penerbangan terbesar adalah kelalaian manusia (faktor manusia), yakni $67,12 \%$, faktor teknis sebesar $15,75 \%$, dan sisanya merupakan faktor lingkungan dan fasilitas. Data diatas menunjukan bahwa kecelakaan pesawat terbang di Indonesia masih tinggi, hal ini menyatakan bahwa tingkat keselamatan penerbangan di Indonesia masih rendah. Hal ini masih jauh dari ekspetasi bila di kaitkan dengan standar keselamatan penerbangan dunia.

Masalah-masalah yang ada ini tidak terlepas dari semakin canggihnya teknologi yang digunakan di dunia penerbangan. Semakin canggih teknologi yang digunakan maka semakin keras juga manusia belajar dalam mengikuti perkembangan teknologi tersebut. Perubahan yang terjadi karena globaliasasi tersebut membawa dampak pada lingkungan bisnis yang meliputi, teknologi dan persaingan produk. Akibatnya perusahaan dituntut untuk meningkatkan kualitas produk, pelayanan, efisiensi, biaya produksi dan meningkatkan produktivitas perusahaan.

Disamping itu, perkembangan teknologi informasi mempunyai dampak yang besar terhadap keunggulan daya saing perusahaan dapat diukur berdasarkan kriteria ekonomi dengan menggunakan ukuran-ukuran seperti efektivitas, efisiensi dan produktivitas. Perkembangan teknologi informasi menciptakan produk dengan kapasitas besar, hemat energi dan dapat melakukan fungsi dan jenis pekerjaan yang semakin banyak serta dengan teknologi informasi dapat mengolah, menyimpan, menampilkan data dan informasi.

Teknologi informasi terbaru itu yang digunakan di maskapai Garuda Indonesia adalah penggunaan Electronic Flight Bag (EFB) sebuah teknologi berbentuk perangkat keras yang fungsinya adalah membantu pilot dan awak penerbangan melakukan tugas-tugas manajemen penerbangan, seperti menyelesaikan kinerja penerbangan dan perhitungan take-off landing lebih mudah dan efisien. Electronic Flight Bag (EFB) juga mempermudah maskapai untuk mengkonfirmasi bahwa pilot sudah memiliki manual dan informasi terbaru, dan untuk mendistribusikan pembaruan bila diperlukan.

Electronic Flight Bag (EFB) sekarang hanya bisa digunakan pada pesawat berbadan besar (wide body) yaitu pada jenis pesawat A330 dan B777 Garuda Indonesia, dan hanya memasukan data yang dibutuhkan saja pada satu penerbangan seperti : Airport Map, Performance Calculation, Terminal Chart, Manual-Manual books. Menurut penelitian yang dilakukan oleh (Haddock \& Beckman, 2015) yang melakukan penelitian membandingkan kerja pilot yang masih menggunakan kertas konvensional dan yang sudah menggunakan Electronic Flight Bag (EFB). Hasilnya menunjukkan peningkatan yang signifikan saat menggunakan Electronic Flight Bag (EFB) dan mengurangi beban kerja atau stres.

Meskipun canggih, teknologi pasti memiliki kekurangan yang akan menyebabkan masalah untuk pesawat maupun maskapai penerbangan itu sendiri, jika ada pembaruan aplikasi Electronic Flight Bag, petugas operation support publication harus mengecek satu persatu dari Electronic Flight bag tersebut sebelum dinaikan kepesawat untuk digunakan. Hal ini terjadi karena belum adanya sistem yang terintegrasi dalam hal pendataan pembaruan Electronic Flight Bag itu sendiri.

Masalah lainnya adalah Electronic Flight Bag yang berisi Navigasi Chart tidak boleh digunakan ketika Critical Eleven yaitu saat tiga menit sebelum lepas landas (take off) dan delapan menit saat ingin mendarat (landing). Namun ada solusi jika Electronic Flight Bag bisa untuk digunakan di Critical Eleven yaitu menerapkan mounting ipad agar pilot dapat masih berkonsentrasi untuk mengendalikan pesawat sekaligus melihat navigasi chart yang ada di Electronic Flight Bag.

Penerbangan tidak terlepas dari budaya keselamatan (safety culture) tiap personal yang berkaitan. Kesadaran budaya keselamatan (safety culture) di dunia penerbangan sangat penting untuk menunjang keselamatan dari suatu misi penerbangan. Kesadaran budaya keselamatan (safety culture) pada penerbangan belum melekat secara utuh dengan terbuktinya masih adanya kecelakaan yang disebabkan oleh faktor manusia.

Berdasarkan latar belakang yang peneliti paparkan diatas maka dapat teridentifikasi berupa masalah sebagai berikut :

1. Penyebab kecelakaan penerbangan di Indonesia di dominasi oleh faktor manusia

2. Belum ada nya sistem yang terintegrasi dengan EFB untuk mengetahuinya ada pembaruan aplikasi

3. Electronic Flight Bag tidak dapat digunakan pada critical eleven

4. Belum melekatnya secara utuh penerapan safety culture

5. Penerbangan yang masih menggunakan kertas konvensional menyebabkan tingkat beban kerja atau stres pilot lebih tinggi dari pada penerbangan yang sudah menggunakan EFB 
Penelitian ini bertujuan sebagai berikut :

1. Untuk mengetahui pengaruh efektivitas Penggunaan Electronic Flight Bag dan Budaya Keselamatan terhadap Kinerja Keselamatan Penerbangan pada PT. Garuda Indonesia

2. Untuk mengetahui pengaruh efektivitas penggunaan electronic flight bag, budaya keselamatan dan kinerja keselamatan penerbangan di PT. Garuda Indonesia secara simultan

3. Untuk mengetahui pengaruh Efektivitas Penggunaan Electronic Flight Bag terhadap Kinerja Keselamatan Penerbangan PT. Garuda Indonesia

4. Untuk mengetahui pengaruh Budaya Keselamatan terhadap Kinerja Keselamatan Penerbangan PT. Garuda Indonesia.

\section{KAJIAN PUSTAKA}

Menurut safety management international collaboration group mendefinisikan safety management system adalah serangkaian proses yang ditetapkan di seluruh organisasi yang menyediakan keputusan berbasis risiko yang efektif terkait dengan bisnis sehari-hari. Menurut ICAO Safety Management System adalah sebagai pendekatan sistematis untuk mengelola keselamatan, termasuk struktur, akuntabilitas, kebijakan, dan prosedur organisasi yang diperlukan.

Persyaratan Safety Management System adalah sebagai pelatihan yang berfokus pada peran yang dimainkan oleh awak kabin individu dalam safety management system operator dan bagaimana kontribusi mereka sesuai dengan gambaran yang lebih besar tentang manajemen keselamatan di tingkat organisasi yang menyeluruh. (Federal Aviation Administration, 2009) mengemukakan empat komponen penting untuk mengembangan safety management system yaitu : kebijakan keselamatan, jaminan keselamatan, manajemen risiko keselamatan, dan promosi keamanaan. FAA menempatkan komitmen manajamen, menetapkan tujuan yang jelas, menentukan metode dan proses untuk memenuhi tujuan keselamatan di bawah kebijakan keselamatan, dan juga menempatkan pelatihan, komunikasi, keselamatan dengan kesadaran, mencocokan persyaratan kompetensi dengan persyaratan sistem dan elemen-elemen lain untuk budaya keselamatan positif di bawah promosi keselamatan.

Menurut (Griffin \& Neal, 2000) Safety performance adalah perilaku kerja yang relevan dengan keselamatan yang dapat dikonseptualisasikan sama dengan perilaku-perilaku kerja lain yang merupakan hasil kerja. Model ini menggabungkan dua komponen dari safety performance yaitu kepatuhan dan partisipasi. Kepatuhan merupakan keterlibatan dan kelekatan pada prosedur keselamatan dan melaksanakan pekerjaan dalam cara yang aman, mempersiapkan dan menggunakan peralatan pengaman yang tepat dalam bekerja. Partisipasi merupakan perilaku keterlibatan yang tidak langsung berhubungan dengan keselamatan individu, namun mendukung terwujudnya lingkungan yang aman.(Griffin \& Neal, 2000). Tujuan mengukur kinerja keselamatan menurut (Jazayeri, 2017) adalah untuk mendapatkan lebih awal tanda peringatan dan bertindak cepat jika tindakan darurat diperlukan, dapat juga sebagai program bonus atau intensif bagi organisasi. Tujuan utama mengukur kinerja keselamatan adalah untuk memeriksa status keselamatan saat ini serta mengamati kemajuan dengan sistem manajemen keselamatan saat ini dibandingkan dengan masa lalu.

Secara umum efektivitas adalah pencapaian tujuan secara tepat atau memilih tujuan-tujuan yang tepat dari serangkaian alternatif atau pilihan cara dan menentukan pilihan dari beberapa pilihan lainnya. Efektivitas bisa juga diartikan sebagai pengukuran keberhasilan dalam pencapaian tujuan-tujuan yang telah ditentukan. Sebagai contoh jika sebuah tugas dapat selesai dengan pemilihan cara-cara yang sudah ditentukan, maka cara tersebut adalah benar atau efektif. Tujuan Penggunaan Teknologi Informasi dalam perpajakan adalah menghemat waktu, mudah, akurat, dan paperless. (Pujiani \& Rizal, 2014). Electronic flight bag (EFB) adalah perangkat/system penghitung/display dan system yang dapat digunakan oleh awak pesawat terbang/pilot untuk berbagai fungsi. Menggunakan EFB dapat mengurangi atau menghilangkan kebutuhan akan kertas dan bahan refrensi lainnya pada kokpit (Allen, 2003) .

EFB singkatan dari Electronic Flight Bag adalah tambahan suatu alat bantu berupa penambahan seperangkat computer untuk memudahkan dan meringankan pekerjaan rutin pilot dan tidak menggunakan kertas lagi ( Less paper cockpit ). Fitur EFB bergantung pada option atau pilihan dari masing-masing airline biasanya airline mempunyai standar option apa saja yang diperlukan untuk penerbangannya dalam EFB yang terpasang dipesawatnya (Setiawan, 2008). Electronic Flight bag (EFB) adalah alat yang memungkinkan awak penerbangan untuk melakukan berbagai fungsi yang secara modern dilakukan dengan menggunakan I-pad dengan mengurangi refrensi kertas. Dalam bentuk yang paling sederhana, EFB dapat melakukan perhitungan 
perencanaan penerbangan dasar dan menampilkan berbagai dokumentasi digital, termasuk bagan navigasi, buku petunjuk operasi, dan daftar pengoperasian pesawat. EFB yang paling canggih sepenuhnya disertifikasi sebagai bagian dari system penerbangan avionic dan terintegrasi dengan system pesawat seperti Flight Management System (FMS).

Electronic Flight Bag dapat di bagi dalam tiga kelas sesuai dengan spesifikasi peralatan ; kelas 1, kelas 2, dan kelas 3.

a. Sistem Electronic Flight Bag kelas 1 :

adalah sistem komputer berbasis comersial-off-shelf (COTS) yang biasa digunakan untuk operasi penerbangan, bersifat portabel, terhubung ke daya pesawat langsung yang sudah tersertifikasi, dianggap sebagai perangkat elektronik portabel terkendali, tidak menggunakan mounting di dalam pesawat, belum memiliki koneksi data pesawat kecuali untuk kondisi tertentu, tidak memerlukan persetujuan kelaikan udara.

b. Sistem Electronic Flight Bag kelas 2 :

Adalah sistem komputer berbasis commercial-off-the-shelf(COTS) yang umum digunakan untuk operasi penerbangan, bersifat portabel, terhubung ke daya pesawat langsung yang sudah tersertifikasi, dianggap sebagai perangkat elektronik portabel terkendali, menggunakan mounting di dalam pesawat, dapat dihubungkan ke sistem avionic, membutuhkan persetujuan kelaikan udara.

c. Sistem Electronic Flight Bag kelas 3

Dipasang sebagai peralatan yang membutuhkan persetujuan kelaikan udara. Persetujuan ini (termasuk intergritas instalasi perangkat keras Electronic Flight Bag, misalnya. Server, layar, keyboard, daya, manuver) mencakup aspek kompatibilitas antar muka manusia dan mesin termasuk kualitas perangkat keras dan perangkat lunak.

Garuda indonesia sendiri menggunakan Electronic Flight Bag kelas 2 untuk penggunakan di pesawat A330/200/300/900 dan B777-300ER. Menggunakan ipad 6 yang berisi manual seperti (OM, FCOM, ROM, FCTM, ACL/Opspec,etc), e-QRH, dan performance calculation software, FLYSMART untuk A330200/300/900 dan OPT untuk B777-300ER, dan e- navigation chart. Menurut (Ateş, 2017) ada enam indikator pengaruh penggunaan EFB di bidang operasional yaitu :

a. Kemudahan akses

b. Lebih banyak informasi (management control dan operation control)

c. Meningkatkan volume informasi.

d. Lebih ringkas dan format lebih baik.

e. Akurat dan bisa diandalkan

Budaya keselamatan adalah seperangkat nilai-nilai dan sikap yang bertahan lama terkait masalah keselamatan, yang dibagikan oleh setiap anggota disetiap level organisasi. Budaya keselamatan mengacu pada sejauh mana setiap individu dan setiap kelompok organisasi menyadari risiko dan bahaya yang tidak diketahui yang disebabkan oleh kegiaannya; selalu berperilaku untuk menjaga dan meningkatkan keselamatan; bersedia dan mampu menyesuaikan diri saat menghadapi masalah keselamatan; bersedia untuk mengomunikasikan masalah keselamatan; dan secara konsisten mengevaluasi perilaku terkait keselamatan.(Piers et al., 2009).

Menurut penelitian yang dilakukan oleh FAA (Federal Aviation Administration (2014) yang di kutip di jurnal (EASA, 2015) yang dihimpun secara sukarela dari organisasi keselamatan penerbangan dari berbagai negara seperti : ASRS (Aviation Safety Reporting System), ATSB (Australian Transportaion Safety Bureau), CAA (Civil Aviation Authority), BEA (French Bureau of Enquiry and Analysis for Civil Aviation Safety), TSB (Transportation Safety Board of Canada).

Melaporkan bahwa banyak terjadinya pilot yang kurang mendapat pelatihan penggunaan electronic flight bag dan belum terbiasanya pilot menggunakan electronic flight bag dari kertas konvensional. Terdapat juga keluhan pilot tentang tampilan electronic flight bag yang terlalu kecil dan informasi didalamnya yang sudah bukan terbaru. Terdapat juga laporan kegagalan sistem electronic flight bag yang tidak dapat di operasikan atau mati total dan masalah kecerahan layar.

Berdasarkan penelitian yang dilakukan Savas S Ates, 2017 Dengan penggunaan sistem EFB, operator dapat mengakses informasi tentang operasi penerbangan dengan lebih cepat dan mudah. Dalam sistem EFB, informasi yang diperlukan oleh pengguna disajikan dalam format yang jauh lebih baik dalam lingkungan elektronik. Informasi disimpan dalam lingkungan elektronik dengan meminimalkan tingkat kesalahan yang disebabkan oleh faktor manusia dan meningkatkan keandalan dan keaslian informasi yang disajikan kepada pengguna. Penggunaan EFB dalam operasi penerbangan memberikan informasi yang lebih akurat untuk 
kontrol operasional pengguna. Dengan menggunakan EFB, dimungkinkan untuk memberikan lebih banyak informasi kepada pengguna yang relevan untuk keperluan kontrol administratif bila perlu.

Menurut penelitian yang dilakukan Sunar Adi Wibowo (2017) budaya keselamatan berpengaruh positif terhadap keselamatan penerbangan. Hal tersebut sesuai dengan teori Edgar H. Schein (2014) tentang budaya organisasi sebagai pola dasar yang diterima oleh organisasi untuk bertindak dan memecahkan masalah, membentuk karyawan yang mampu beradaptasi dengan lingkungan dan mempersatukan anggota-anggota organisasinya.

Hasil penelitian yang dilakukan Bandura, Guldenmund maupun Arjen Balk tentang Safety Culture atau budaya keselamatan yang merupakan seperangkat nilai dan sikap abadi mengenai keselamatan yang dimiliki oleh setiap anggota pada tiap tingkat organisasi. Budaya keselamatan tersebut mengacu pada sejauh mana setiap individu dan setiap kelompok organisasi mengetahui resiko dan bahaya yang tidak terlihat yang disebabkan oleh kegiatan, bagaimana tetap berperilaku sehingga dapat mempertahankan dan meningkatkan keamanan, bersedia dan mampu menyesuaikan diri saat menghadapi masalah keselamatan, bersedia mengkomunikasikan isu-isu keselamatan, serta secara konsisten mengevaluasi perilaku terkait keselamatan. Kerangka berpikir dalam penelitian sebagai berikut :

\section{Gambar 1. Kerangka Berpikir}

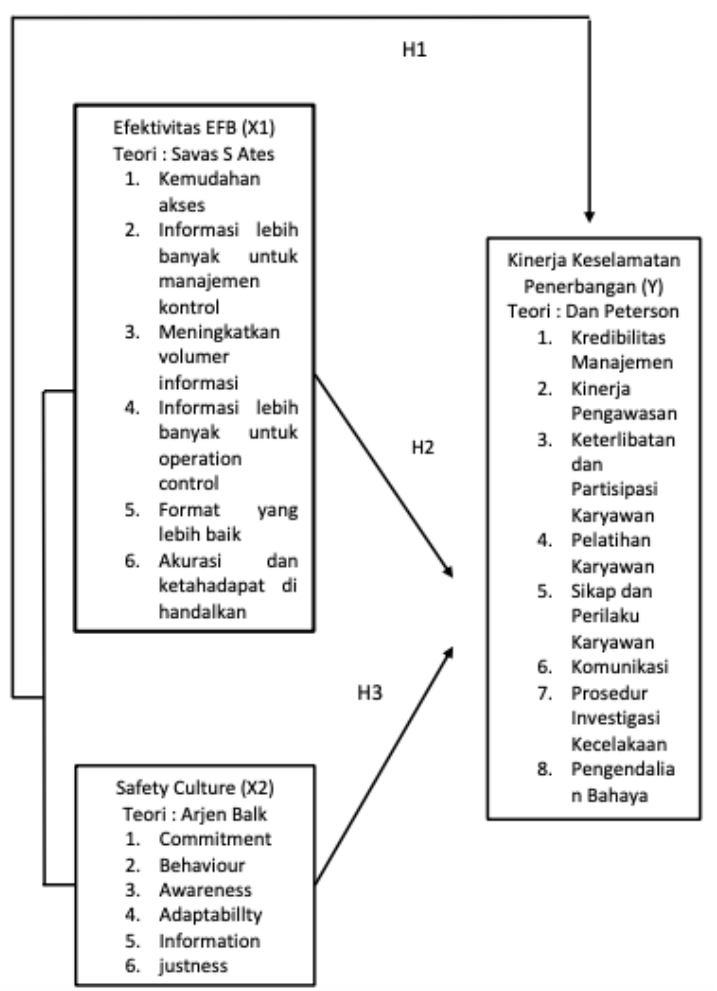

Hipotesis pada penelitian ini sebagai berikut :

H1 : Efektivitas penggunaan EFB dan Budaya Keselamatan secara bersama-sama berpengaruh positif terhadap kinerja keselamatan penerbangan di PT. Garuda Indonesia

H2 : Efektivitas penggunaan EFB berpengaruh positif dan signifikan terhadap kinerja keselamatan penerbangan PT. Garuda Indonesia

H3 : Budaya Keselamatan berpengaruh positif dan signifikan terhadap kinerja keselamatan penerbangan PT. Garuda Indonesia

\section{METODE}

Data yang digunakan dalam penelitian ini adalah data primer yang diperoleh dengan menyebarkan kuesioner yang disebarkan secara online kepada sampel 35 pilot Garuda Indonesia yang mengkhususkan diri dalam menerbangkan pesawat Airbus A330. Teknik analisis yang digunakan adalah analisis deskriptif 


\section{Analisis Koefisien Korelasi Berganda}

Koefisien korelasi berganda ini digunakan untuk mengetahui seberapa besar hubungan variabel independen (efektivitas EFB dan budaya keselamatan) dan variabel dependen (kinerja keselamatan penerbangan) berikut ini adalah hasil perhitungan koefisien korelasi berganda :

Tabel 3. Koefisien Korelasi Berganda

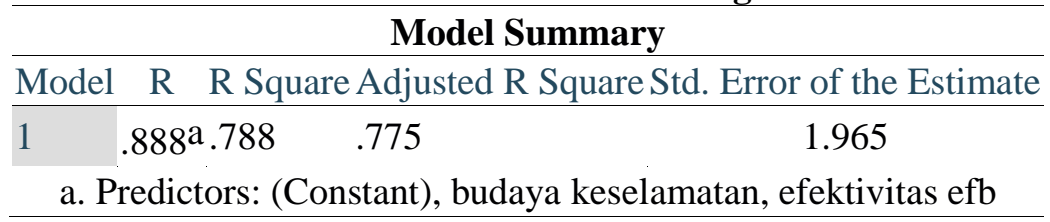

Nilai koefisien korelasi berganda $\mathrm{R}=0,888$. Dengan demikian besarnya hubungan efektivitas $\mathrm{EFB}$ dan budaya keselamatan terhadap kinerja keselamatan penerbangan PT. Garuda Indonesia adalah 0,888 pada interval 0,80-1,000 berarti mempunyai hubungan yang sangat kuat, searah positif. Koefisien determinasi ini digunakan untuk mengetahui seberapa besar kontribusi atau perebuhan yang diberikan variabel independen terhadap variabel dependen didapat dengan rumus sebagai berikut :

$$
\mathrm{KD}=\mathrm{R}^{2} \times 100 \%
$$

Maka, $\mathrm{KD}=0,788 \times 100 \% \mathrm{KD}=78,8 \%$

Dengan demikian besarnya kontribusi pengaruh efektivitas penggunaan electronic flight bag dan budaya keselamatan terhadap kinerja keselamatan penerbangan PT. Garuda Indonesia adalah 78,8\% dan isanya $21,2 \%$ merupakan pengaruh dari faktor lain. Untuk mengetahui ada tidaknya pengaruh secara bersama- sama (simultan) antara semua variabel independen (efektivitas EFB dan budaya keselamatan) terhadap dependen (kinerja keselamatan penerbangan) sebagai berikut :

1. Ho : $\mathrm{p}=0$, artinya jikai nilai sig $>0,05$, atau Fhitung $<$ Ftabel maka tidak teradpat pengaruh variabel $\mathrm{X}_{1}$ dan X2 secara simultan terhadap variabel Y.

2. Ha : $\mathrm{p}=0$, artinya jikai nilai sig $<0,05$, atau Fhitung $>$ Ftabel maka teradpat pengaruh variabel $\mathrm{X} 1$ dan $\mathrm{X} 2$ secara simultan terhadap variabel $\mathrm{Y}$.

Tabel 4. Uji F Anova

\begin{tabular}{llllll}
\hline & $\begin{array}{c}\text { Sum of } \\
\text { Squares }\end{array}$ & df & Mean Square & F & Sig. \\
\hline Regression & 458.758 & 2 & 229.379 & $59.421 .000^{\mathrm{b}}$ \\
\hline Residual & 123.528 & 32 & 3.860 & \\
\hline Total & 582.286 & 34 & & \\
\hline
\end{tabular}

a. Dependent Variable: kinerja keselamatan penerbangan

b. Predictors: (Constant), budaya keselamatan, efektivitas efb

\section{Sumber : Data Olahan SPSS}

Menetapkan tarif nyata (a)/ tingkat keyakinan (1-a) untuk mencari ta (a) $=5 \%$ atau tingkat keyakinan (1a) $=1-5 \%=95 \%$, karena dengan semakin besar tingkat kepercayaan maka akan semakin akurat hasil yang diperoleh. Maka penulis memilih uji statistik dengan rumus sebagai berikut menggunakan tabel $\mathrm{F}$

Ftabel $=\mathrm{F}(1-\mathrm{a})\{(\mathrm{dk}=\mathrm{k}),(\mathrm{dk}=\mathrm{n}-\mathrm{k})\}=\mathrm{F}(1-\mathrm{a})\{(\mathrm{dk}=2),(\mathrm{dk}=33-2)\}$

$=\mathrm{F}\{(1-0,05)(2,33)$

Cara mencari Ftabel $=2$, sebagai pembilang $=33$, sebagai angka penyebut Ftabel $=3,28$ Berdasarkan perhitungan Uji F menggunakan SPSS, maka diperoleh Fhitung sebesar , 59,421 yang berarti bahwa :

1. $\quad 0,000<0,05$, maka dari hasil tersebut Ho ditolak dan Ha diterima.

2. $59,421>3,28$, maka dari hasil tersebut Ho ditolak dan Ha diterima.

Model persamaan regresi yang dapat dituliskan dari hasil tersebut dalam bentuk persamaan regresi linier adalah sebagai berikut :

$Y=-19,191+0,112 X_{2}$

Dari pengujian secara parsial berdasarkan tabel 4.15 dapat diperoleh pengaruh variabel efektivitas EFB terhadap kinerja keselamatan penerbangan, dimana diketahui bahwa tingkat signifikan sebesar 0,000 dan 
thitung sebesar 5,012. Dan dari jumlah responden (n) yaitu sebanyak 35 orang maka dapat diperoleh ttabel adalah sebesar

tabel $=\mathrm{t}(\mathrm{a} / 2)(\mathrm{n}-\mathrm{k}-1)=\mathrm{t}(0,025)(35-2-1)=\mathrm{t}(0,025(32)=2.03693$

Dari data tersebut maka diperoleh hasil :

1) $0,000<0,05$, maka dari hasil tersebut Ho ditolak Ha diterima.

2) 5,012 > 2.03693, maka dari hasil tersebut Ho ditolak Ha diterima.

Maka dari hasil diatas menunjukan bahawa variabel efektivitas EFB memberikan pengaruh yang signifikan dan positif terhadap kinerja keselamatan penerbangan PT. Garuda Indonesia.

\section{KESIMPLAN DAN SARAN}

1. Efektivitas electronic flight bag yang terdapat pada kinerja keselamatan penerbangan dalam kategori sangat efektif. Indikator terendah terdapat pada butir pernyataan nomor 2 (EFB menyediakan lebih banyak informasi tentang manajemen kontrol). Indikator tertingggi terdapat pada butir pernyataan nomor 6 (EFB meningkatkan akurasi dan keandalan informasi).

2. Budaya keselamatan terdapat pada kinerja keselamatan penerbangan dalam ketegori sangat baik. Indikator terendah terdapat pada butir pernyataan nomor 42 (metode pelaporan yang disepakati memuaskan). Indikator tertingggi terdapat pada butir pernyataan nomor 22 (latihan yang baik membuat pegawai lebih mampu mengatasi bahaya (hazard) yang ada).

3. Kinerja keselamatan dalam kategori sangat baik. Indikator terendah terdapat pada butir pernyataan nomor 3 (tingginya keterlibatan atau partisipasi pegawai dalam setiap safety meeting). Indikator teringgi terdapat pada butir pernyataan nomor 9 (overtime pekerjaan menyebabkan stress).

4. Berdasarkan hasil penelitian dapat ditarik kesimpulan bahwa dari hasil analisis regresi berganda diperoleh $\mathrm{Y}=-19,191+1,161 \mathrm{X} 1+0,112 \mathrm{X} 2$, yang artinya setiap terjadi perubahan satu satuan variabel $\mathrm{X}_{1}$ akan diikuti dengan perubahan pada nilai variabel Y sebesar 1,161 kali, atau perubahan satu satuan variabel efektivitas electronic flight bag meningkat 1,161 skor variabel kinerja keselamatan penerbangan PT. Garuda Indonesia, tiap terjadi perubahan satu satuan variabel $\mathrm{X}_{2}$ akan diikuti dengan perubahan pada nilai variabel Y sebesar 0,112 kali, atau perubahan satu satuan variabel budaya keselamatan meningkat 0,112 skor variabel kinerja keselamatan penerbangan PT. Garuda Indonesia.

5. Dari uji koefisien korelasi berganda dan dihubungkan dengan interpretasi didapatkan hasil dari nilai $r$ sebesar 0,888 berada pada interval $0,80-1,00$ yang mana artinya terdapat hubungan yang sangat kuat antara efektivitas electronic flight bag dan budaya keselamatan terhadap kinerja keselamatan penerbangan.

6. Hasil perhitungan koefisien determinasi atau koefisien penentu hasil nilai sebesar $77,8 \%$, yang mana artinya bahwa kontribusi yang diberikan oleh efektivitas electronic flight bag dan budaya keselamatan terhadap kinerja keselamatan penerbangan adalah sebesar 77,8\%. Adapun sisanya sebesar $21,2 \%$ merupakan pengaruh dari variabel lain yang tidak diteliti.

7. Berdasarkan hasil pengujian hipotesis secara simultan, menunjukan Fhitung $=59,421>$ Ftabel $=3,28$ dan signifikansi sebesar $0,000<0,05$, maka dari hasil tersebut Ho ditolak dan Ha diterima. Dilihat dari nilai koefisien korelasi berganda $\mathrm{R}=0,888$ berarti besarnya efektivitas electronic flight bag dan budaya keselamatan terhadap kinerja keselamatan penerbangan PT. Garuda Indonesia adalah 0,888 berarti mempunyai pengaruh sangat kuat, searah positif.

8. Berdasarkan hasil pengujian hipotesis secara parsial antara variabel efektivitas EFB (X1) terhadap variabel kinerja keselamatan penerbangan (Y) pada PT. Garuda Indonesia, dimana thitung $=3,638>$ ttabel 2,03693 dan signifikansi sebesar 0,001 $<0,05$ maka dari hasil tersebut Ho ditolak Ha diterima.

9. Berdasarkan hasil pengujian hipotesis secara parsial antara variabel budaya keselamatan (X2) terhadap variabel kinerja keselamatan penerbangan $(\mathrm{Y})$ pada PT. Garuda Indonesia, dimana thitung $=5,012>$ ttabel 2,03693 dan signifikansi sebesar 0,000 < 0,05 maka dari hasil tersebut Ho ditolak Ha diterima. 


\section{Daftar Pustaka}

llen, D. (2003). Electronic Flight Bag. Aero, July, 16-27.

Ateş, S. S. (2017). Electronic Flight Bag in the Operation of Airline Companies: Application in Turkey. Computer Science and Information Technology, 5(4), 128- 134. https://doi.org/10.13189/csit.2017.050402

Chase, S. G., \& Hiltunen, D. (2014). An examination of safety reports involving electronic flight bags and portable electronic devices. June.

Dan, P. (2005). Measurement of safety performance. American Society of Safety Engineers, 2005.

EASA. (2015). EFB Electronic Flight Bag Aircraft performance calculations and mass \& balance. 3. https://www.easa.europa.eu/sites/default/files/dfu/EASA-Research- Rep-2014-1.pdf

Faisal. (1990). Penelitian Kuantitatif, Dasar dan Aplikasi.

Federal Aviation Administration. (2009). Safety Management System Components.

https://www.faa.gov/about/initiatives/sms/explained/components/

Griffin, M. A., \& Neal, A. (2000). Perceptions of safety at work: a framework for linking safety climate to safety performance, knowledge, and motivation. Journal of Occupational Health Psychology, 5(3), 347358. https://doi.org/10.1037/1076- 8998.5.3.347

Haddock, K. N., \& Beckman, W. S. (2015). The Effect of Electronic Flight Bag Use on Pilot Performance during an Instrument Approach.

Jazayeri, E. (2017). Safety Management System and Methods of Safety. February. https://doi.org/10.13140/RG.2.2.26892.10882

National Business Aviation Association. (2018). electronic flight bags. https://nbaa.org/aircraftoperations/communications-navigation-surveillance- cns/electronic-flight-bags/

Piers, M., Montijn, C., \& Balk, A. (2009). Safety Management System and Safety Culture Working Group ( SMS WG ) SAFETY CULTURE FRAMEWORK FOR THE ECAST SMS- WG. ECAST : European Strategic Safety Initiatives, March, 1-14.

Poerwanto, E., \& Mauidzoh, U. (2017). Analisis Kecelakaan Penerbangan Di Indonesia Untuk Peningkatan Keselamatan Penerbangan. Angkasa: Jurnal Ilmiah Bidang Teknologi, 8(2), 9. https://doi.org/10.28989/angkasa.v8i2.115

Pujiani, M., \& Rizal, E. (2014). Analisis Efektivitas Penggunaan E-system Terhadap Penerimaan Pajak di KPP Pratama Palembang Illir Timur. Jurnal Akuntansi S1, 1-9.

Purba Hasim. (2017). Jurnal Hukum Samudra Keadilan. 12, 95-110.

Setiawan, B. (2008). electronic flight bag. http://www.ilmuterbang.com/artikel- mainmenu-29/teoripenerbangan-mainmenu-68/45-electronic-flight-bag

Sugiyono. (2017). Metode Penelitian Kuantitatif.

Wibowo, S. A., \& Pertahanan, U. (2017). the Effect of Airmanship and Safety Culture on the Aviation. 1-24. 